\title{
Personal style of cognition (cognitive traction) and the level of involvement of the student (engagement) in the assessment and development of digital competencies of the teacher
}

\author{
O. M. Chorosova, G. S. Solomonova*, N. Yu. Tulasynova, A.Z. Alekseeva, and \\ M.V. Ivanov \\ North-Eastern Federal University, Yakutsk, Russia
}

\begin{abstract}
The article presents the results of the intermediate stage of the research conducted within the framework of the project of the Russian Foundation for Basic Research No. 19-29-14030 "Cognitive models and algorithms for the formation of digital competence of a teacher in the conditions of digitalization of general education". The project is aimed at improving the effectiveness of the teacher's activities in the context of digitalization of education by developing the digital competence of the teacher through the introduction of cognitive models and algorithms for evaluating the digital competencies of teachers and making decisions on the design or adjustment of professional development programs. The current state of the problem of professional and personal development of teachers in the context of digitalization of education, their digital competence, approaches to the identification of digital competencies and their assessment is studied, conceptual approaches to the identification of digital competencies of teachers are defined and the main indicators of their assessment are developed. At the second stage (2021), a structural model of the organization of professional development of teachers is being developed, taking into account the requirements of digitalization of general education on the basis of a competence-based approach. There is also the task of developing a cognitive model of the advanced training program (ATP), which allows us to take into account the strength of the links between the studied modules and digital competencies based on the application of an algorithm for assessing the significance of disciplines. The results of this work are proposed for discussion in this article.
\end{abstract}

\section{Introduction}

Currently, there is an understanding of the "lessons of the pandemic", with the onset of which the entire Russian education system in extreme conditions switched to online mode and distance learning, a rethinking of the ideas and traditional approaches in the education system

\footnotetext{
* Corresponding author: solomonovags@mail.ru
} 
that existed before March 2020. It was a real stress test that changed the views of all participants in the educational process, revealed many problems that require immediate, immediate solutions in order to be able to respond to new challenges. These challenges are associated with key teacher deficits and the need to develop mechanisms to overcome them. First of all, we are talking about the shortage of digital competencies of teachers in Russian schools. When the research project was at the very beginning of implementation, the authors could not even imagine how much its relevance would increase in the spring of 2021.

\section{Materials and methods}

\subsection{Literature review}

In the Russian educational space, the problem of developing the ability to use information and communication technologies, today - digital competencies, of a teacher has always been given serious attention, which is increasingly increasing in the process of digitalization of school education. This is evidenced by many scientific, scientific and practical conferences devoted to the topic of modern educational strategies in the information society, the representation of the educational space in the cyber space, methods of teaching various subjects in the context of digital transformation of the school, information security [1-9].

The pandemic has taught both teachers and children virtual forms of classes, access to various databases, to primary sources that have become available on the Internet today; teamwork, the use of multimedia technologies: the need for continuous education is now becoming a need for everyone. At the same time, the total informatization of all spheres of human life generates the greatest number of risks [2, 4], among which the threat to the wellbeing and safety of children is in the first place.

The qualitative characteristics of a modern teacher capable of constructing or modeling a personal style of cognition (cognitive traction) through an individual educational trajectory and involving students (engagement) are now formulated in active qualifications submitted for discussion by the Council for Professional Qualifications in Education: these are machine learning specialist, educational data engineer, educational designer and educational technologist - promising professions developed at the University 20.35. But today we have to admit that neither didactics, nor the theoretical foundations and methodology have yet been developed to the necessary extent

The processes of informatization have a significant impact on the content of education and its information and didactic tools, but its theoretical foundations and methodology [1012].

All of the above actualizes the problem of identifying, evaluating and developing digital competencies of a teacher.

The level of technological development in the field of education directly and completely depends today on the level of development of digital competencies of the teacher. In the development of tools and an automated system for identifying and evaluating digital competencies of teachers of the Republic of Sakha (Yakutia): the methodology and research tools of the NAFI Analytical Center were studied [12].

The main research methods are: methods of system analysis - in the development of a structural model of the organization of professional development of teachers, the analysis of the content of the digital competence of the teacher, the development of criteria for assessing the compliance of the professional development program with the requirements of digitalization of the educational process; methods of mathematical modeling - in the creation of an algorithm for assessing the significance of modules of professional development programs and algorithms for their adjustment; methods of cognitive modeling - in the 
development of cognitive models of digital competence of a teacher and professional development programs; methods of managerial decision-making - in the development of an algorithm for an automated decision support system when adjusting professional development programs; methods of fuzzy logic in the process of fuzzy assessments of the significance of competencies; methods of sociological research - in the study of the effectiveness of the proposed approach in professional development of teachers.

\section{Results and Discussion}

The personal style of cognition (cognitive traction) and the level of involvement of the student (engagement) in the educational process with the possibility of self-assessment of the level of formation of educational results became the basic elements in mapping the process of identifying and evaluating the formation of digital competencies of the teacher in this study.

In modern Russian and foreign science, a sufficient amount of research has been accumulated on cognitive learning theories and methods of cognitive mapping [13 - 18].

According to Ginis Ginis, cognitive modeling provides an opportunity for fundamentally new solutions in the process of cognitive activity - for forecasting and planning [19].

The methodology that synthesizes the system and cognitive approaches can become a universal scientific tool for understanding the behavior of complex systems [20], since the scenario method allows analyzing the cause-and-effect relationships in the system under consideration; analyzing its stability and developing control solutions [19]. This approach, which allows us to take into account the strength of the links between the modules being studied and digital competencies, has become a reference for the project team in building a cognitive map of the teacher's digital competencies, as well as a cognitive model of the professional development program.

The developed universal algorithm for making a decision on the adjustment of the ATP in accordance with the changes in the requirements for the digital competencies of the teacher includes the following stages:

1) development of a matrix of professional (digital) competencies;

2) development of the main indicators for evaluating the results (digital competencies), the scale of their assessment;

3) identification and assessment of the level of formation of digital competencies among teachers:

a) teachers ' assessment of the importance of digital competencies;

b) self-assessment of teachers of the current state of formation of digital competencies;

c) identification and assessment of the level of formation of digital competencies among teachers using various approaches and tools (automated system (tester program "Simulator of digital competencies of a teacher"), etc.) and determination of qualification deficits of teachers in the field of digital competencies for their translation into educational results;

4) identification of compliance of professional development programs with the main indicators of the formation of digital competencies among teachers;

5) making management decisions on the adjustment and development of advanced training program (ATP).

On the basis of the competence matrix (the methodology of Postalyuk N.Yu., Bobienko O.M.), the qualification deficits of teachers in the field of digital competencies are identified for their translation into educational results.

Thus, the study conducted on the generalization of the results of the assessment of the formation of digital competencies of teachers in an automated system [21], as well as using the method "Matrix of digital competencies of a teacher" with the participation of 224 teachers showed the following results. 
The "gap" between the high significance of a particular competence and the low level of formation of this competence among teachers was found in the following key competencies:

- skills of verifying information in various ways: checking information from the site in other authoritative sources, evaluating the reputation of the site, finding information about the author (source) of the material, etc.: $38.6 \%$ and $41.6 \%$, respectively;

- working with cloud technologies to provide participants of the educational process with remote access to services and applications via the Internet (cloud file storage, cloud office: maintaining electronic diaries and rating journals, personal accounts of teachers and students), online surveys, testing, interactive reception rooms, thematic chats and forums for students and trainees, search for information on a given topic, etc.): $49.1 \%$ and $35.9 \%$, respectively;

- use of digital tools in the process of creating an electronic educational resource (integration of animation, multimedia, interactive elements, etc.): $53.6 \%$ and $38.7 \%$;

— the ability to create complex interactive digital learning materials and activities, for example, interactive worksheets, online assessment tools, interactive collaborative learning activities (for example, wikis, blogs), games, applications, visualizations: $41.8 \%$ of respondents recognize high significance; $36.1 \%$ and $26 \%$ of teachers, respectively, note a low and very low level of formation of this competence.

- the ability to develop their own means of communication: $51.4 \%$ of teachers note a high degree of significance and $33.5 \%$ and $22 \%$ of respondents have it formed at a low and very low level, respectively;

- the ability to develop their professional competencies in the field of improving the level of digital development of students: $60.9 \%$ highly appreciated the importance of this competence, while $40.9 \%$ of teachers rated the level of its formation as low;

- knowledge of the skills of searching among existing or creating new various technological methods and tools to solve the problem based on a critical analysis of their advantages and disadvantages and teaching this to students: $53 \%$ and $41.7 \%$, respectively;

- ability to critically evaluate their own educational technologies for the development of digital competence of students: $52.5 \%$ and $42.4 \%$, respectively.

For the vast majority of digital competencies, significant "qualification gaps" were found, when teachers, recognizing their high importance, evaluated the current level of formation of these competencies, choosing " 0 " - the complete absence of such competence:

- -Competence "Industrial design and 3d modeling": 44\% and 25.1\%, respectively;

- Cybersecurity and data protection: $57.1 \%$ and $13 \%$;

- Programming and creation of IT products: $52.5 \%$ and $22.1 \%$;

- Mobile robotics: $50.7 \%$ and $30.4 \% \%$;

- Mobile app development: $48.8 \%$ and $35.4 \% \%$;

- System administration: $44.2 \%$ and $22.3 \% \%$

— Digital marketing and media: $40.5 \%$ and $30.2 \% \%$;

- Sensors and robotics components: $39.5 \%$ and $39.4 \%$;

— Internet of Things: $36.9 \%$ and $26.3 \%$;

- Development of computer games and multimedia applications: $43.9 \%$ and $38.8 \%$;

— Electronics and radio engineering: $40.4 \%$ and $42.3 \%$;

— Digital design: $48.6 \%$ and $28.6 \%$ of teachers, respectively.

Based on the results obtained in 2020 the Institute of Continuing Professional Education has developed a modular professional development program "Digital didactics of a modern teacher" (developer of the variant part - Alekseeva A.Z., Senior lecturer of the Department of Andragogy of the Institute of Continuing Professional Education of the North-Eastern Federal University), currently, within the framework of this project, the process of filling the contents of the following variable modules is underway: "Working with data: educational 
data engineering" (16 hours), "Pedagogical design in the construction of IOT" (16 hours), "Digital Methodologist" (16 hours), "Fundamentals of Machine learning" (16 hours). This choice was due to the fact that currently there is a process of professional and public discussion of the qualifications "Educational Data Engineer", "Educational Technologist (digital Methodologists)", "Machine Learning Specialist" and "Pedagogical Designer", initiated by the Council for Professional Qualifications in Education (https://spkobr.ru/dokumenty/dokumenty-na-obsuzhdenii/).

Thus, the module "Working with data: educational data engineering" is aimed at developing skills starting from the 4th level of qualification (basic level): at this level, knowledge (general principles of building databases, concepts and structure of the digital footprint, technological platforms that supply the digital footprint, principles of conducting interviews, requirements of legislation on personal data protection, methods and means of information protection) and skills (to use means of storing and transmitting information to work with the digital footprint; to use data flow models to monitor the download process; conduct interviews with the target audience; use technology platforms to collect feedback; depersonalize primary data) should be sufficient for the teacher to perform the following work function: verification of the digital footprint markup by interviewing information carriers and decision makers; monitoring the download of digital footprint data through the user interfaces of technology platforms, monitoring the download of datasets of aggregated or point data about the digital footprint; setting up user feedback collection tools; monitoring the download of data and materials confirming productive participation in the activity; analysis of the received digital footprint data. If the 4th and 5th skill levels are assigned to the basic level, then the 6th, respectively, is to the middle level, and the 7 th and 8 th are to the highest level.

A detailed description of the knowledge, skills and work function here guides us to the educational results that must be achieved in the learning process. Thus, the 7 th level of qualification involves the teacher mastering knowledge from data visualization methods, research of the results of the introduction of technologies for analyzing human data (groups of people) to project management methods and the basics of research activities, etc.; skillsto visualize and interpret the results of analysis, choose and apply methods for studying the results of research of the results of the introduction of technologies for analyzing human data (groups of people), to conduct a comparative analysis of data for compliance with established standards, etc. - in order to be able to perform the work function, which at this level includes testing the model of human activity, validating the model of human activity (groups of people); filling and adjusting the content of the model of human activity (groups of people), designing the process of transmitting and storing digital footprint data, etc. These characteristics by qualification levels are reflected in the "Map of Digital Teacher Competencies" developed at the first stage and currently being supplemented.

Of course, the qualifications submitted by the Council for Professional Qualifications in Education for discussion by the pedagogical professional community today seem at first glance to be "promising professions of the future", which has nothing to do with the reality in which teachers work today. But this is only at first glance. If we say that high-quality management decisions can be made primarily on the basis of data analysis, then it becomes obvious that the school should either have a professional data engineer who will contribute to making competent management decisions, or the set of professional competencies of the teacher should include competencies from the field of digital competencies: working with data and managing them; pedagogical design, higher level (7th level) which involves knowledge of trends in interactive technologies, media and educational technologies, data engineering, etc., e-learning skills, prototyping and design skills, knowledge of specialized software products, storytelling skills, strategic planning, tutoring, etc. to perform the work function, including the coordination of educational projects, the design of educational 
experience, the development of adaptive educational programs, e-courses, the development and configuration of the assessment system, the formation of development plans, etc.; educational technologist (digital methodologist), whose work functions include: technological support of educational technologies (pedagogical), support of users of educational programs, podyor and implementation of educational technologies for achieving optimal solutions to educational problems, etc., and at the 7th, higher, qualification level, the functions already include participation in the development of educational materials, analysis of the effectiveness of the use of pedagogical and digital technologies in education, development, testing, testing and implementation of educational models, etc.

\section{Conclusion}

So, based on the testing of an automated system for identifying and evaluating the formation of digital competencies of teachers of the Republic of Sakha (Yakutia) and the generalization of the data obtained, in the process of analyzing existing professional development programs for teachers, the need to improve certain digital competencies of a teacher necessary for solving professional tasks in the context of digital transformation of the school was revealed. The modular professional development program for the development of digital competencies of the teacher will be tested, the forms and content will be adjusted, and the final version of the educational product will be offered by the beginning of the new academic year.

\section{Acknowledgments}

The work was carried out with financial support Russian Foundation for Basic Research (Project No. 19-29-14030).

\section{References}

1. R. Aetdinova, O. Chorosova, I. Maslova, Int. Scientific Conf. "Far East Con" (ISCFEC 2020), 2678

2. R. Aetdinova, G. Galiullina, G. Solomonova, Int. Scientific Conf. "Far East Con" (ISCFEC 2020), 2685

3. Yu. Aetdinova, R. Rasulya, R. E. Gerasimova, \& N. T. Zakharov, The Bulletin The National Academy Of Sciences Of The Republic Of Kazakhstan, 6 (2020)

4. R. R. Aetdinova, O. M. Chorosova, G. S. Solomonova, Economic and Humanitarian Sciences, 11 (2020)

5. Educational space in the Information age (EEIA-2016): collection of scientific papers of the Int. Scientific and Practical Conf. on June 6-7, 694 (2016)

6. Educational space in the information age-2019 (International conference "Education Environment for the Information Age - 2019") (EEIA - 2019): collection of scientific papers, 1,378 (2019)

7. Strategy for the development of the educational space in the context of global risks: Collection of scientific papers of the Int. Scientific and Practical Conf., 220 (2017)

8. Technologies of cognitive training in the conditions of digital transformation of educationcollection of materials of the scientific and educational forum of the NorthEastern Federal University with international participation "Education, forward!" (2020)

9. O. M. Chorosova, R. R. Aetdinova, G. S. Solomonova, G. Y. Protodyakonova, Education and Self-Development, 15(3), 2020 
10. N. V. Belyaeva, Informatization of school literary education (2019)

11. S. Young, According to the results of the international scientific conference "eSTARS 2017": Innovations and undermining the traditional education system in the digital age

12. T. A. Aimaletdinov, Digital literacy of Russian teachers. Readiness to use digital technologies in the educational process, 88 (2019)

13. A. R. Kamaleeva, S. Yu., Gruzkova, O.V. Sofinskaya, N. V. Shigapova, Recent trend in Science and Technology management, 1(2)

14. Cognitive educational psychology, https://studme. org/

15. E. L. Bogdanova, O. E. Bogdanova, Bulletin of TSU, 353, 161 (2011)

16. J. Portugali, COSIT 2005, LNCS 3693, 251

17. M. Garabet, Procedia Social and Behavioral Sciences 2, 2, 3622 (2009)

18. M. Pinto, J. of Information Science, 36(4), 464 (2010)

19. L. A. Ginis, Izvestiya TRTU

20. V. I. Maksimov, E. K. Kornoushenko, S. V. Kachaev, Cognitive technologies to support management decision-making

21. Computer program "Automated system" Key competencies of a teacher in the conditions of digital transformation of education" (2021) 